\title{
Variability in adsorptive phosphorus removal by structural stormwater best management practices
}

\author{
Shawn E. Rosenquist ${ }^{\mathrm{a}, *}$, W. Cully Hession ${ }^{\mathrm{b}, 1}$, Matthew J. Eick ${ }^{\mathrm{c}, 2}$, David H. Vaughan ${ }^{\mathrm{d}, 1}$ \\ a Biological Systems Engineering, VA Tech, 203 Seitz Hall, Blacksburg, VA 24061, United States \\ ${ }^{\mathrm{b}}$ Biological Systems Engineering, VA Tech, 304 Seitz Hall, Blacksburg, VA 24061, United States \\ ${ }^{\mathrm{C}}$ Crop E' Soil Environmental Science, VA Tech, 330 Smyth Hall (0404), Blacksburg, VA 24061, United States \\ d Biological Systems Engineering, VA Tech, 308 Seitz Hall, Blacksburg, VA 24061, United States
}

\section{A R T I C L E I N F O}

\section{Article history:}

Received 24 July 2009

Received in revised form

10 December 2009

Accepted 17 December 2009

\section{Keywords:}

Phosphorus

Wetlands

Nutrients

BMP

Eutrophication

Urban

Stormwater

\begin{abstract}
A B S T R A C T
Various best management practices (BMPs) utilizing sorption processes (SP) have demonstrated effectiveness for phosphorus $(\mathrm{P})$ management in stormwater. However, the widespread use of these BMPs in urban areas has been limited by large land requirements and limited $\mathrm{P}$ removal capacity. Central to this study is the development of the urban wetland filter (UWF), a concept intended to overcome these limitations and provide a low-cost, easily implemented BMP that can meet urban P-management goals. Performance variation along with finite sorption capacity has limited the reliability of SP as a primary removal strategy. However, if variability were better understood and capacity made renewable, sorption of $\mathrm{P}$ to substrates could provide the option of a more rapid and (with less required retention time) more space-efficient sustainable removal strategy than biological uptake. The goal of this study was to identify and model major sources of variability in P removal by sorption, enabling better prediction and optimization of sorption performance and ultimately the development of a small-footprint stormwater BMP with efficient P removal ability. Experiments were conducted in bench-scale reactors with an iron-oxide sand substrate. Results included a physical-process model developed by considering the thermodynamic and kinetic properties of SP. Significant sources of variability included, by order of importance, magnitude of a solution/substrate concentration gradient, length of the "antecedent dry period" between loadings, and $\mathrm{pH}$. Most importantly, results indicate the critical importance of a thermodynamic gradient between solution $\mathrm{P}$ and previously adsorbed $\mathrm{P}$ to achieve continued removal.
\end{abstract}

(c) 2009 Elsevier B.V. All rights reserved.

\section{Introduction}

Eutrophication, driven largely by excess nutrients in surface runoff, is a significant problem in US surface waters (Parry, 1998). Eutrophication can cause environmental degradation and also has significant economic impacts on coastal fisheries and municipal drinking water supplies (Camargo and Alonso, 2006). Phosphorus $(P)$ is often the target nutrient for preventing eutrophication because it is the limiting factor for algal growth in some saltwater and almost all freshwater systems (Fisher et al., 1992) and because it does not have a process analogous to denitrification to prevent buildup in surface water through transition to the atmosphere.

\footnotetext{
* Corresponding author. Tel.: +1 540231 6615; fax: +1 5402313199. E-mail addresses: serosenq@vt.edu (S.E. Rosenquist), chession@vt.edu (W.C. Hession), eick@vt.edu (M.J. Eick), davaugha@vt.edu (D.H. Vaughan).

1 Tel.: +1 540231 6615; fax: +15402313199.

2 Tel.: +1 540231 6305; fax: +1 5402313431 .
}

Urban areas are of particular interest for non-point source $\mathrm{P}$ management as adverse water quality has been correlated to both the density and speed of urbanization (Atasoy et al., 2006). Urban $P$ loads can rival those of agricultural land uses (Paul and Meyer, 2001) and urban environments have unique constraints such as high land-value and rapid hydrologic response that complicate stormwater treatment. Traditional urban stormwater management often utilized dry detention ponds and focused on peak flow attenuation while doing little to address nutrient impacts. More recently, wet retention ponds designed with permanent pools have been introduced in an effort to address stormwater quality along with quantity (Carleton et al., 2000; Hogan and Waldbridge, 2007). These stormwater ponds are ubiquitous in the American urban landscape with an estimated 2.6 million such ponds across the contiguous US (Smith et al., 2002). Retention ponds provide some water quality treatment, mostly by sedimentation, but remove little dissolved phosphorus (DP) (Comings et al., 2000). However, retention ponds do provide a unique opportunity to extend available treatment time for the water retained. This extended treatment time can be 
utilized more productively by incorporating an add-on BMP positioned off-line from stormwater flow, optimized for removing DP, and continuously filtering retained water. This strategy is similar to one used by Coveney et al. (2002) with a wetland on Lake Apopka, but with a decentralized, smaller-scale approach.

Other BMPs have been investigated for urban stormwater treatment, including stormwater wetlands (Carleton et al., 2000; Kadlec and Wallace, 2009) and have performed effectively, but land availability is a common limitation. Traditional designs are often land intensive and not economically feasible in urban areas (Hunt and Wossink, 2003). Biological uptake followed by organic accretion in sediments is the typical strategy for long-term $P$ removal in these BMPs (Kadlec and Wallace, 2009) but also drives the large land requirements (Kadlec, 2005). This process is not, however, the only P removal process involved. Sorption processes (SP), mainly adsorption at stormwater concentrations, can effectively sequester DP and do so more rapidly than biological uptake (Lantzke et al., 1999). A rapid removal mechanism can enable shorter residence times for treatment, increase allowable flow rates, and decrease required BMP size. However, reliance on SP for removal has limitations including large variability in performance and finite sorption capacity (Kadlec and Wallace, 2009). While some of this variability can be attributed to performance metrics, including volume reductions (USEPA, 2002), significant variability remains.

Though understood to be based on saturation processes (Kadlec and Wallace, 2009), P removal by BMPs that rely on SP is often conceptualized by practitioners as a first-order model with a constant removal percentage at stormwater concentrations (VDCR, 1999). This removal percentage is assumed constant regardless of changes in internal parameters (such as substrate type, redox potential, and $\mathrm{pH}$ ) or external parameters (such as flow rate and "antecedent dry period") that have been suspected of causing variation (Carleton et al., 2000; Pant et al., 2001; Farahbakhshazad and Morrison, 2003; Naylor et al., 2003; Arias and Brix, 2005; Shilton et al., 2005).

Alternatively, P removal by SP could be conceptualized with a physical-process model using the thermodynamic and kinetic principles associated with SP and the internal and external parameters subject to variation. Thermodynamics involved in P removal by SP are described by isotherm curves, which are used extensively in soil chemistry to provide often published sorption capacities for various substrates. Isotherm curves represent the thermodynamic possibility for a reaction to occur based on the nature of the adsorbent and given concentration of the adsorbate (McBride, 1994). Therefore, it is reasonable to conclude that influent concentration, representing the concentration of the adsorbate, as well as $\mathrm{pH}$ and $P$ sorption history, representing the nature of the adsorbent, may function interactively to determine the thermodynamic probability of further P removal.

Kinetics associated with SP have been described by Arai and Sparks (2007) who divide the kinetics of specific adsorption into two reactions: (1) rapid (hours or less) adsorption limited by the ligand exchange process; and (2) slower (days to months) adsorption limited by diffusion into pore spaces and the subsequent enabling of further ligand exchange. Therefore, it is also reasonable to include diffusion-related variables such as filter age, flow rate, or the timing of loadings to predict $P$ removal.

The objectives of this study were: (1) to validate DP removal by SP using iron-oxide sand substrate; (2) to identify major sources of variability in P removal by SP; and (3) to determine whether a physical-process model can provide significantly better P removal prediction than a first-order model. These objectives are part of the multi-study development of a novel stormwater BMP for urban $P$ management, the urban wetland filter (UWF). The UWF concept pairs small $\left(<140 \mathrm{~m}^{2}\right)$, vertical-flow (VF) wetland cells with an existing retention pond. The off-line cell does not need to be sized for peak flows and can either re-circulate water from the pond (with pumping) or serve as the low-water outlet for the pond (without pumping). Cell size is decreased compared to a typical stormwater wetland by a periodic rejuvenation process based on microbial reduction of iron $(\mathrm{Fe})$ enabling controlled release of adsorbed $P$ from the substrate (Lovley, 1991). In addition, the ability of the retention pond to sequester sediment-bound $P$ (Comings et al., 2000) is incorporated, allowing the UWF cells to be optimized for DP removal. Further design choices for the UWF seek to optimize SP, including: (1) use of substrate high in iron-oxides to provide adsorptive capacity and ability for rejuvenation (Darke and Walbridge, 2000); (2) upward, VF for minimum size (Luederitz et al., 2001), maximum mixing, and minimal clogging (Farahbakhshazad and Morrison, 2003); and (3) low residence time $(<1 \mathrm{~h})$ to promote aerobic conditions (Farahbakhshazad and Morrison, 2003).

\section{Materials and methods}

\subsection{Experimental setup}

Six experimental UWF cells (Fig. 1) were set up in a climatecontrolled laboratory space, which maintained a temperature of $22 \pm 4{ }^{\circ} \mathrm{C}$. Water for the cells was supplied from a constant head tank (CHT) located in the center of the cells. The CHT received water from a 265-L plastic holding tank (HT) that served as the "eutrophic retention pond" for this study. The cells were similar in construction and scale to those used by Prochaska and Zouboulis (2006). Some scaling problems have been associated with field applicability of bench-scale studies on SP, specifically in regards to quantification of performance (Kadlec and Wallace, 2009). While all quantitative results should be viewed in this perspective, the objectives of this study also led to qualitative conclusions that should be more resistant to scaling problems.

Cells contained the following horizontal layers, listed from bottom to top: a 76-mm layer of medium-sized gravel (\#8 stone), where the inlet structure was located; a 254-mm layer of USDAgrade medium sand $(0.5-1 \%$ Fe by mass); and a $50-\mathrm{mm}$ layer of standing water (Fig. 2). Sand was sourced from a pit quarry in New Castle, VA.

The experiment included a series of 20-h runs of the six cells, including both treatment and control runs, with only one cell receiving flow during a particular treatment run while the other cells remained saturated without flow. During treatment runs, flow started in the holding tank where a submersible pump brought water to the CHT. A hydraulic head of $5.5 \mathrm{~cm}$ in the CHT drove the water through one UWF cell and back into the holding tank. Water entered the UWF cell in the gravel layer at the bottom of the cell through a bulkhead fitting for horizontal distribution before flow-

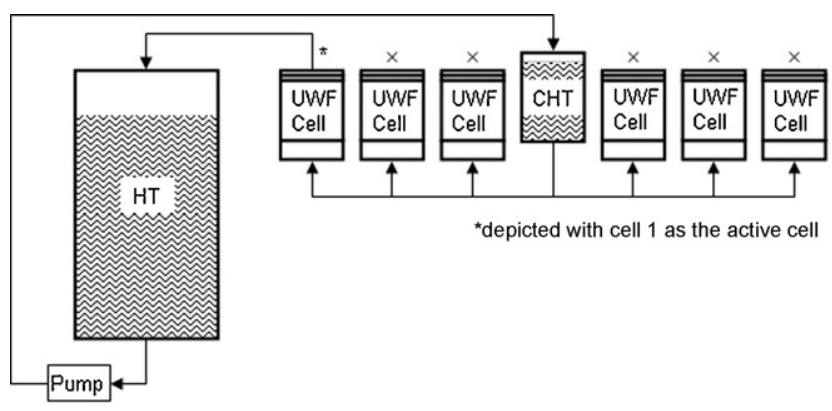

Fig. 1. The six replicate UWF cells were supplied water from a constant head tank located in the center of the six cells. The CHT had water supplied from a 265-L plastic holding tank that served as a "eutrophic retention pond." 


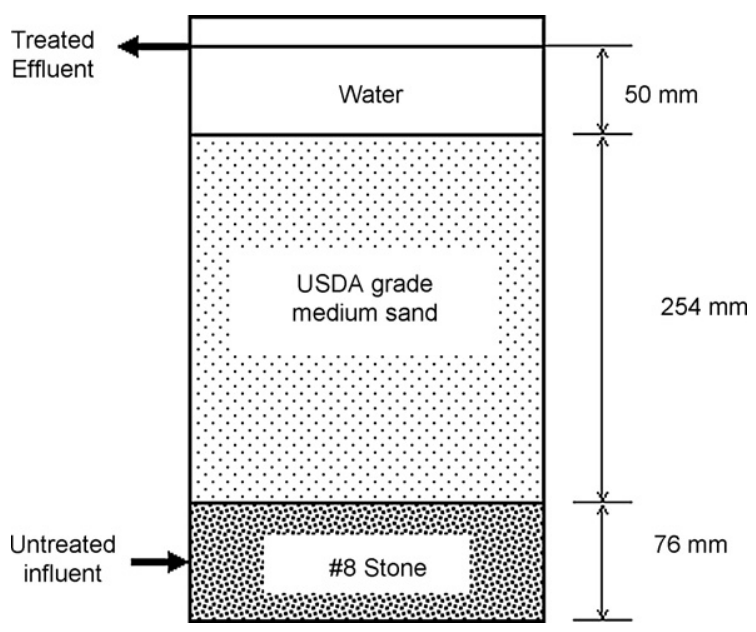

Fig. 2. An individual UWF cell consisted of horizontal layers from bottom to top including: gravel, sand, and standing water.

ing upward through the sand layer. This bottom to top, VF regime is similar to that used by Evans and Rusch (2007) except for the fixed boundaries in this study. During control runs, flow proceeded from the HT to the CHT, and directly back to the HT, completely bypassing the UWF cell. In this way, any unanticipated P removal in the experimental setup, apart from that due to P removal in the cell, could be identified. Fifteen treatment runs were performed with each cell for 90 total treatment runs. Four control runs were performed after the treatment runs. Water used was a synthetic stormwater created by adding an inorganic $P$ solution to distilled water to achieve concentrations between $0.1 \mathrm{mg} / \mathrm{L}$ and $0.6 \mathrm{mg} / \mathrm{L}$. These concentrations were consistent with samples taken from stormwater ponds in the Blacksburg, VA, area that represented a range in both depth and distance between inlet and outlet (Table 1). P concentrations in the synthetic stormwater, mostly DP, were consistent with TP concentrations in the ponds. The water in the HT was periodically augmented during the study with additional inorganic $\mathrm{P}$ solution to maintain concentrations in the desired range, and distilled water to offset evaporation.

\subsection{Experimental design}

Independent variables included the filtration "age" of the cell, initial DP concentration in the HT, and "antecedent dry period" between flow events. The dependent variable was the mass of $P$ removed by the wetland cell during a given filtration run, measured by changes in HT concentration. Results are presented as mass removed instead of removal percentage because it proved more useful towards identifying sources of variability. Additional monitored, but uncontrolled, variables of interest included cell $\mathrm{pH}$ and flow rate. These variables were included in anticipation that they may prove to be of interest in explaining the results of the experiment.

Table 1

Phosphorus concentrations and total loads from 4 stormwater ponds in Blacksburg, VA.

\begin{tabular}{lllll}
\hline Pond & $\begin{array}{l}\text { \# of } \\
\text { samples }\end{array}$ & $\begin{array}{l}\text { Avg. TP } \\
(\mathrm{mg} / \mathrm{L})\end{array}$ & $\begin{array}{l}\text { Estimated } \\
\text { volume }(\mathrm{L})\end{array}$ & $\begin{array}{l}\text { Total resident } \\
\text { P load }(\mathrm{kg})\end{array}$ \\
\hline 1 & 6 & 0.19 & $2.90 \mathrm{E}+06$ & 0.56 \\
2 & 4 & 0.18 & $5.80 \mathrm{E}+06$ & 1.04 \\
3 & 5 & 0.26 & $2.40 \mathrm{E}+06$ & 0.63 \\
4 & 5 & 0.24 & $2.30 \mathrm{E}+06$ & 0.55 \\
\hline
\end{tabular}

All concentrations given as mass of $\mathrm{P}$.

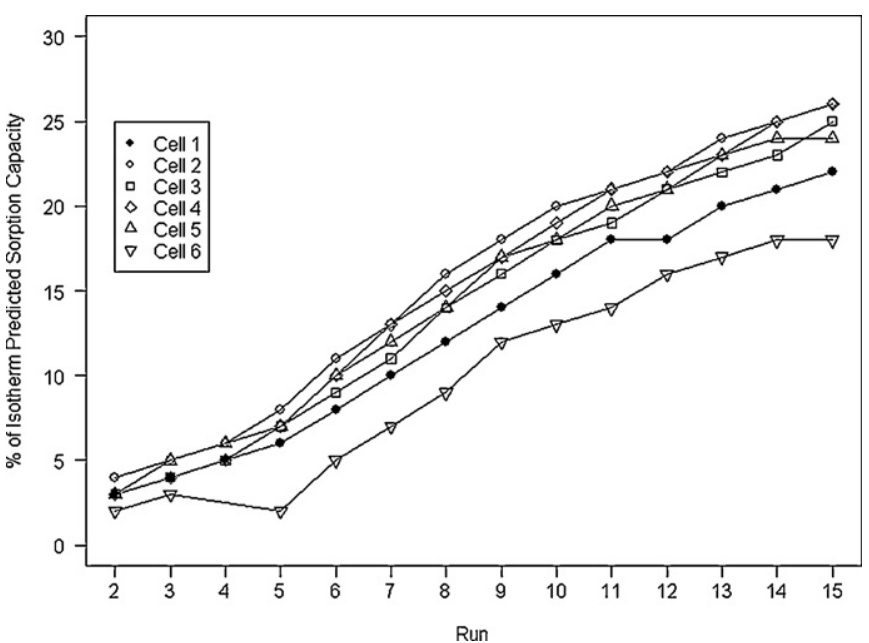

Fig. 3. During the study, cells increased from below $5 \%$ to around $25 \%$ of isothermderived sorption capacity.

\subsection{Isotherm testing}

To describe the "age" of the filter, a theoretical sorption maximum was established for the substrate to serve as a reference point. The total mass of $P$ removed in each cell compared the calculated maximum, thus providing a filter "age" as the percent of the maximum that had been reached (Fig. 3). This isotherm procedure was conducted with the sand substrate according to standard soil testing procedures similar to those described by Arias et al (2001). Key differences from cited study were that $10 \mathrm{~g}$ of substrate were used for each 200-mL sample container, samples were analyzed by Inductively Coupled Plasma Atomic Emission Spectroscopy (ICP-AES), and no containers were included for analysis without substrate. The theoretical maximum was determined with the linear form of the Langmuir equation:

$\frac{C}{q}=\frac{1}{k b}+\frac{C}{b}$

where $C$ is the equilibrium concentration of the adsorptive, $q$ is the adsorbed quantity, $k$ is a constant related to the binding strength, and $b$ is the sorption maximum. The result was a sorption maximum of $45 \mathrm{mg}-\mathrm{P} / \mathrm{kg}$ which relates to approximately $1125 \mathrm{mg}-\mathrm{P}$ for each $25-\mathrm{kg}$ sand filter. For comparison, a recent study of two small ( $<1$ ha), highly urbanized catchments in the Chesapeake Bay watershed found contributions of $900 \mathrm{mg}-\mathrm{P} / \mathrm{ha} / \mathrm{yr}$ and $3600 \mathrm{mg}$ $\mathrm{P} / \mathrm{ha} / \mathrm{yr}$ (Li and Davis, 2009). A study from the Great Lakes observed urban watersheds contributing as much as 23,000 mg-P/ha/yr during development and 300-4800 mg-P/ha/yr after development (Sonzogni et al., 1980).

\subsection{Sampling procedure}

Data collection for this study took place between January 2008 and January 2009. All water samples were taken from the HT. Samples were taken before, after, and in some cases throughout the 20-h runs and analyzed for DP to track removal in each run of each cell. An automated sampler (ISCO 3700, Lincoln, NE) was used for the first 33 runs sampling from the HT at 5-h intervals throughout the run to ensure a proper sampling interval. Once temporal trending was well established, samples were collected by hand from the $\mathrm{HT}$ at the beginning and end of each run. The mass of $\mathrm{P}$ removed during each specific run was determined with the known volume of the HT. 


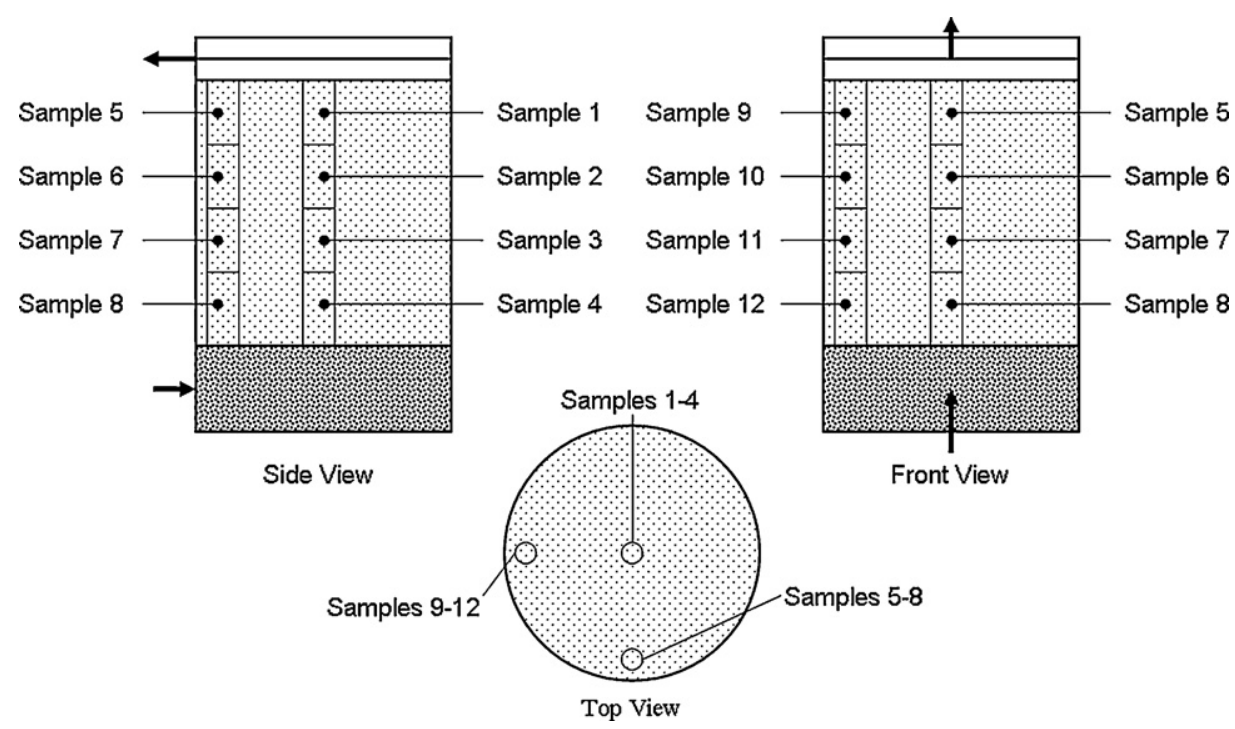

Fig. 4. Substrate samples were taken with 5 -cm diameter soil coring equipment from top to bottom of the sand layer at three different locations in the filter.

The initial flow rate was set near $0.2 \mathrm{~L} / \mathrm{min}$. This flow rate was chosen based on trial runs conducted in conjunction with this study. It represented a safe maximum to avoid disruption of the sand media by fluidization. Flow rate was estimated by volumetric capture into a graduated cylinder $(500 \mathrm{~mL})$ while timing with a stopwatch. Two measurements were averaged with the previously calculated flow rate to estimate a representative flow rate for a given run. Two $\mathrm{pH}$ measurements were taken for each run with a handheld $\mathrm{pH}$ pen (Hanna Instruments, Woonsocket, RI) in the standing water portion at the top of the UWF cell, once before flow was started and once at the end of the run. The $\mathrm{pH}$ pen was periodically calibrated with standard buffer solutions.

\subsection{Spatial distribution procedure}

Previous studies have indicated the existence of spatial gradients of adsorbed $P$ in substrates with the amount of adsorbed $P$ decreasing in the direction of flow (Drizo et al., 2000). An existing spatial gradient of $P$ could coincide with an existing thermodynamic gradient and continued capacity for $\mathrm{P}$ removal. By this theory, little or no spatial gradient would be expected if a quasi-equilibrium thermodynamic condition had been reached. A condition of no existing spatial gradient would be indicated by very little or no statistical difference from samples taken in spatial positions ranging from inlet to outlet of the UWF cells following completion of the last run.

After the filtration runs, substrate samples were taken on a three-dimensional grid in the UWF cell (Fig. 4). Samples were taken with $5-\mathrm{cm}$ soil coring equipment through the entire depth of the sand layer at three cell locations, two at the side and one in the middle. Samples were taken 6 months after removal runs. After coring, samples were oven dried for $24 \mathrm{~h}$, then analyzed for Fe and P with supernatant analysis by ICP-AES after extraction with sulfuric and hydrochloric acids.

\subsection{Modeling}

Data from the experiment were used to test two different models: (1) a first-order model; and (2) a physical-process model. Regressor variables for the first-order model included influent concentration, filter "age," $\mathrm{pH}$, and flow rate. If $\mathrm{P}$ removal percentages were consistent, then mass removal should have a positive linear correlation with influent concentration, but not with $\mathrm{pH}$ or flow rate. Correlation with filter "age" might be expected as sorption sites are filled.

The physical-process model included the following regressor variables: (1) concentration gradient, where $\mathrm{P}$ removal may be positively correlated with a concentration gradient between the previous adsorption equilibrium of the adsorbent and current influent concentration of adsorptive (larger increases in influent concentration from previous equilibrium would favor more adsorption); (2) pH, where P removal may be inversely correlated with $\mathrm{pH}$ (adsorption of stronger acid anions in soils is generally favored at lower $\mathrm{pH}$ values (McBride, 1994)); (3) flow rate, where P removal may be correlated with flow rate (lower flow rates might favor additional adsorption if the process is diffusion-controlled, or alternatively lower flow rates might favor anaerobic conditions and less adsorption) and; (4) "antecedent dry period", where P removal may be positively correlated with the time between runs (kinetic limitation based on diffusion between runs opening additional adsorption sites).

The key difference between these two models is that in the physical-process model additional adsorption may not occur even though there are still "available" sites as predicted by the theoretical maximum based on isotherm testing. Additional concentration gradient might be established by the following methods: (1) introducing additional free sorption sites as with new substrate; (2) removing adsorbed $P$ from the media and into solution; (3) increasing the influent concentration of DP; or (4) diffusion of P into micropores, thereby freeing the original sorption sites. Testing this model made use of two variables calculated from the data set. The first variable, "concentration gradient", quantified the increase in the influent concentration between the end of the previous run (assumed quasi-equilibrium) and the beginning of the following run, for which the removal mass is to be predicted. The second variable, "antecedent dry period", quantified the length of time between runs of a given cell. This variable represents a kinetic effect such as diffusion of $\mathrm{P}$ into micropores, freeing up external sorption sites and increasing the thermodynamic gradient.

\subsection{Data management}

Sampling complications occurred on two runs, including a battery failure on the automated sampler and a valve failure resulting 


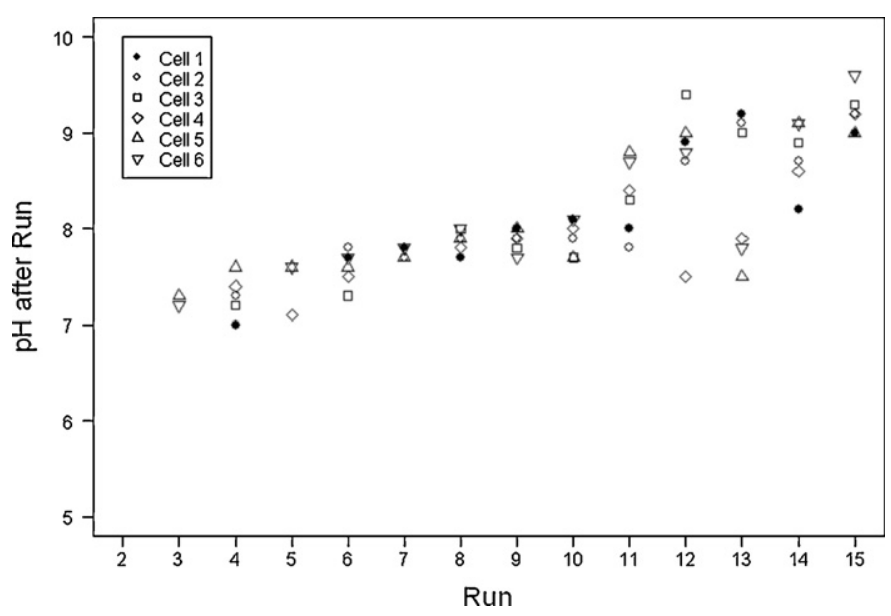

Fig. 5. A general increase in $\mathrm{pH}$ for all wetland cells was observed.

in water leakage. The battery failure run was excluded from the data set since no data were available. Data were gathered for the valve failure run and were included since the $P$ removal could be adequately estimated. Also, without direct comparison of the influent and effluent concentrations, it was somewhat difficult to determine whether complete equilibrium had been reached at the end of the 20-h run and the term quasi-equilibrium is used. However, any expected error based on this assumption should under-predict the effect of the gradient since runs with lower calculated gradients would be biased more heavily than runs with higher calculated gradients by any carryover between runs.

\subsection{Sample analysis}

Samples from the first two treatment runs were analyzed with a colorimetric technique involving premeasured reactants, while samples from the remaining 13 treatment runs and the control runs were analyzed by ICP-AES. This procedure was conducted in accordance with EPA Method 200.7 (USEPA, 1994). After direct comparison of samples analyzed by both methods, the ICP-AES method reported equivalent concentrations with less standard error and more quality control than the available colorimetric technique. $\mathrm{P}$ in the samples was differentiated as DP by gravimetric settling and could include some suspended forms of P. However, this differentiation is probably more consistent with $P$ not removed by sedimentation.

\subsection{Statistical analysis}

Data analysis was conducted using the "R" statistical software package (R Development Core Team, 2009). The Shapiro-Wilkes test for normality and Welch's $t$-test were used for comparing means of $\mathrm{P}$ mass removal between control and treatment runs. Analyses of the various proposed sources of variability utilized multivariable regression analysis and backward model selection. The associated model assumptions were verified by graphical residual analysis.

\section{Results and discussion}

\section{1. $\mathrm{pH}$ and flow rate trends}

During the study, $\mathrm{pH}$ values were neutral to alkaline and increased in general (Fig. 5). This was expected because the specific adsorption of $\mathrm{P}$ is a ligand exchange reaction, which includes a

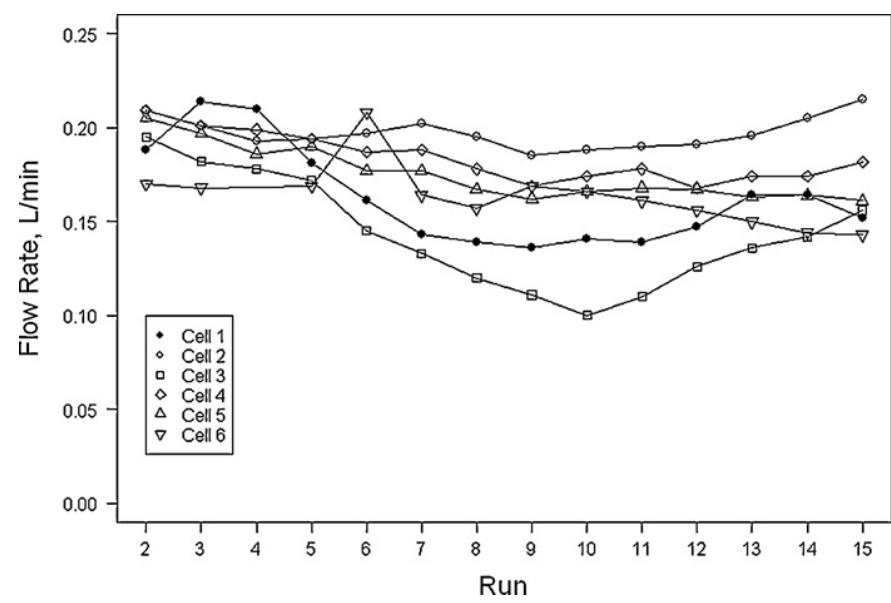

Fig. 6. Flow rates observed during runs varied both across and within cells, however, such changes were generally within a factor of two.

release of hydroxide ions (McBride, 1994). The tendency to increase $\mathrm{pH}$ may be an important factor for BMP designers, and supports the inclusion of $\mathrm{pH}$ buffering materials. Flow rates varied both between and within cells (Fig. 6). A general trend was also noted, with most cells experiencing a decrease in flow rate over time. Since TSS was not a factor in this experiment, any decrease was probably due either to settling of the substrate or biofouling.

\subsection{Validation of P removal by iron-based substrate}

Comparison of data from treatment and control runs verified the ability of an iron-based media filter to remove DP (Fig. 7; $p=0.025$; Welch's two-sample $t$-test). On average, the iron-based media filterers removed $18.16 \mathrm{mg}$-P per run while the average removal for the control runs was not statistically different from $0 \mathrm{mg}$-P per run. Any removal during control runs could be due to biological uptake by microorganisms or sorption to plastic containers and tubing. These results support the use of iron-substrates in BMP design for increased P removal performance by SP.

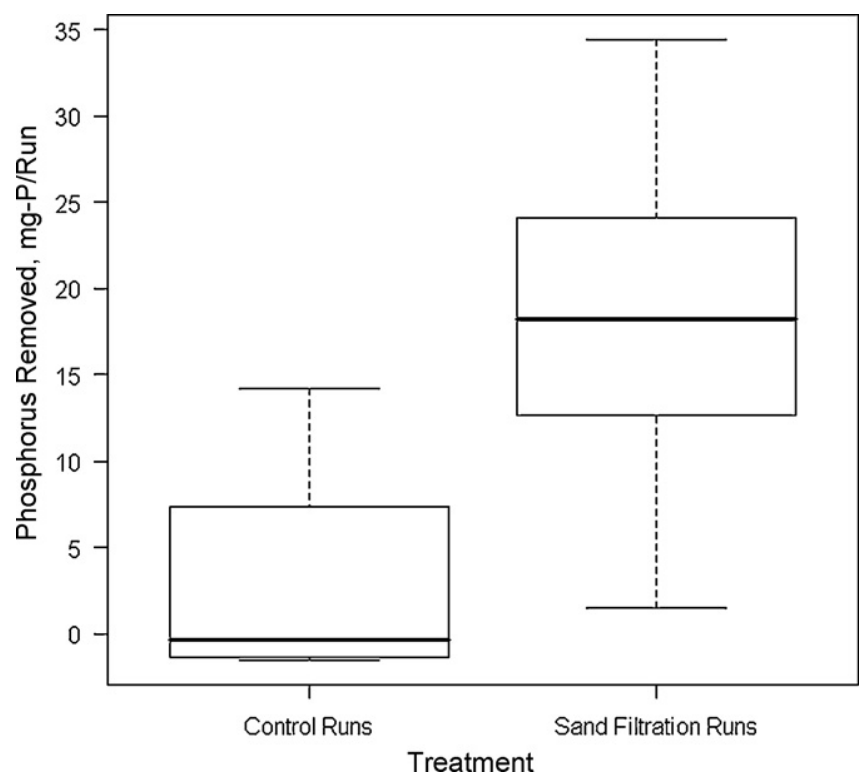

Fig. 7. Iron-oxide sand filtration demonstrated a significant $P$ removal capability compared to control runs without iron-oxide sand filtration (plot depicts: $Q_{1}-1.5$ Interquartile Range; $Q_{1}$; Median; $Q_{3} ; Q_{3}+1.5$ Interquartile Range). 
Table 2

Regression details for first-order model of P removal.

\begin{tabular}{lll}
\hline Coefficient & $p$-Value & Estimate \\
\hline Intercept & 0.0006 & 58.9 \\
Filter age (\%SC) & 0.9715 & $\mathrm{~N} / \mathrm{A}$ \\
Initial influent concentration & 0.7173 & $\mathrm{~N} / \mathrm{A}$ \\
$\mathrm{pH}(\mathrm{pH}$ units) & 0.0208 & -2.37 \\
Flow rate (L/min) & 0.8078 & $\mathrm{~N} / \mathrm{A}$ \\
$R^{2}$ & $\mathrm{~N} / \mathrm{A}$ & 0.14 \\
\hline
\end{tabular}

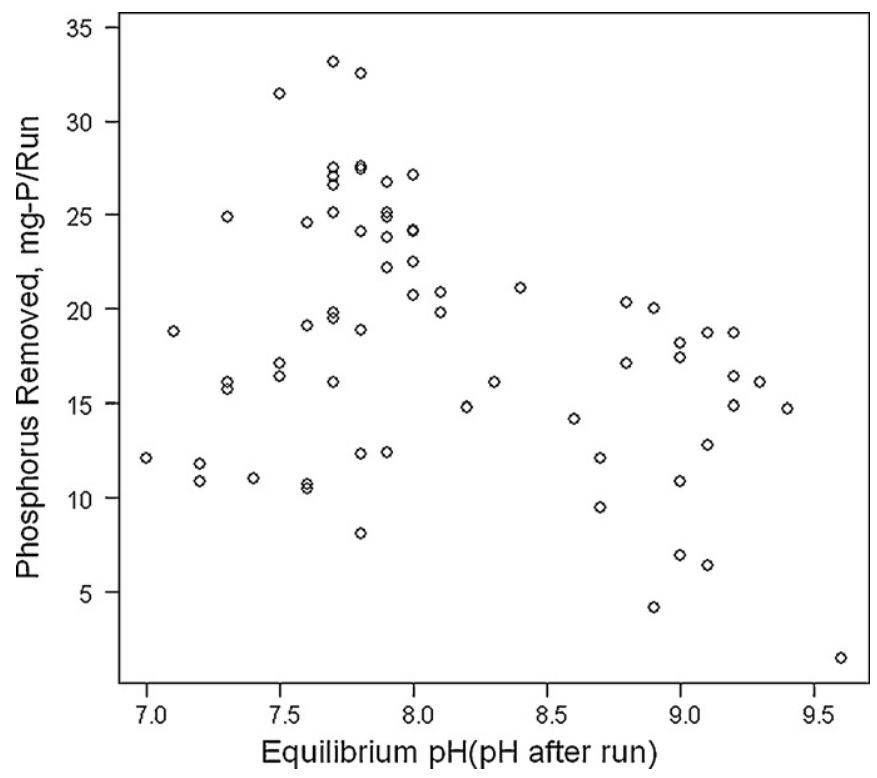

Fig. 8. Equilibrium pH taken after the 20-h treatment run displays a weak negative correlation to P removal for that run.

\subsection{First-order model}

Of the four variables included in this model (Table 2), only $\mathrm{pH}$ was significant $(p=0.0208)$, and provided limited explanation for variability (Fig. 8). It is notable that neither influent concentration nor filter "age" was significant in the model, indicating that a constant removal percentage was not demonstrated and that current influent concentrations alone may be a weak predictor of $P$ removal by SP. Results also show that the percent of sorption capacity filled is a poor predictor of removal decay.

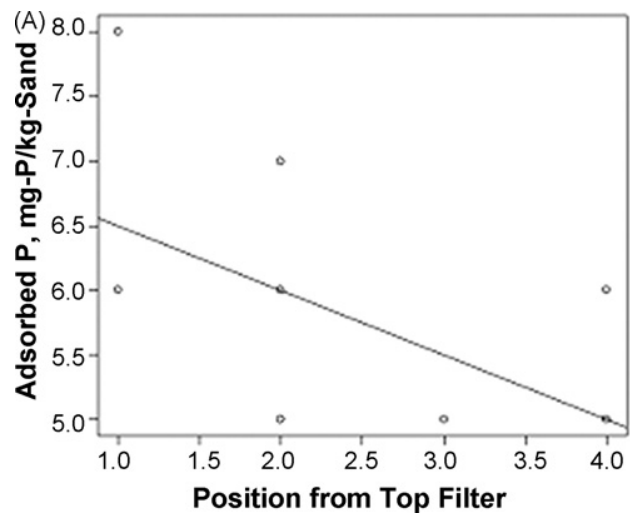

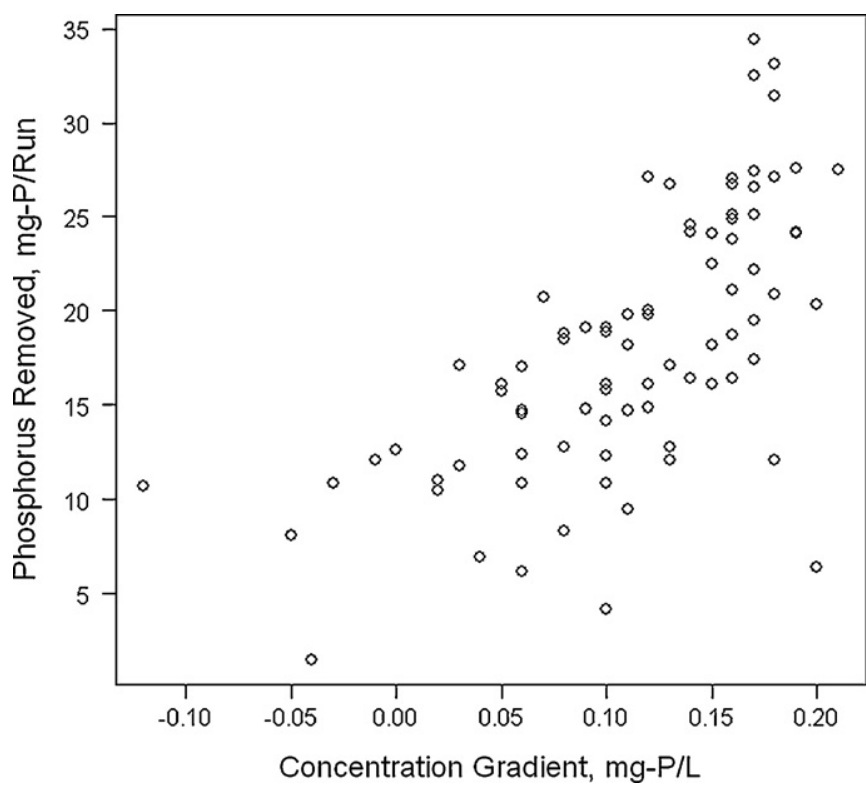

Fig. 9. Initial concentration gradient was a strong predictor of P removal during the runs.

Table 3

Regression details for physical-process model of P removal.

\begin{tabular}{llc}
\hline Coefficient & $p$-Value & Estimate \\
\hline Intercept & $1.78 \mathrm{E}-06$ & 5.277 \\
Initial influent concentration & $2.56 \mathrm{E}-15$ & 10.46 \\
Rest (days) & $1.12 \mathrm{E}-02$ & 2.62 \\
$\mathrm{pH}$ (pH units) & $1.26 \mathrm{E}-05$ & -4.75 \\
$R^{2}$ & $\mathrm{~N} / \mathrm{A}$ & 0.70 \\
\hline
\end{tabular}

\subsection{Physical-process model}

In addition to a significant negative correlation with $\mathrm{pH}$, "concentration gradient" and "antecedent dry period" demonstrated significant positive correlation to P removal in this model (Table 3). Of particular interest, the "concentration gradient" variable may, at least partially, explain the mechanism associated with "irreducible concentrations" reported in previous studies (Schueler, 1996; Strecker et al., 2001). Significance of the "antecedent dry period" variable is consistent with a study which also predicted a positive correlation with flow rate using bench-scale studies with VF wetland cells (Farahbakhshazad and Morrison, 2003). The absence of a correlation with flow rate in this study could be due

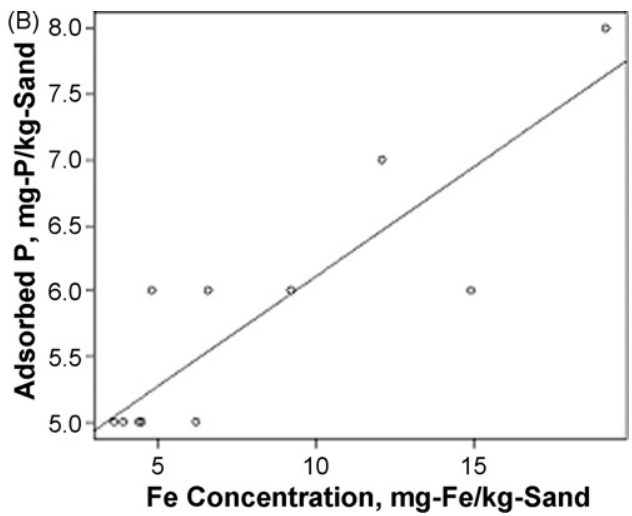

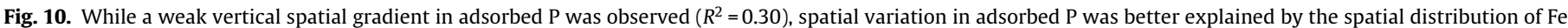
$\left(R^{2}=0.74\right)$ 
to the relatively small range in flow rates. The negative correlation with $\mathrm{pH}$ is consistent with the findings of Zeng et al. (2004) and a field-based study by Redshaw et al. (1990). Regarding the relative influence of the significant variables, "concentration gradient" had by far the largest effect, followed by $\mathrm{pH}$, and lastly the diffusion-related, "antecedent dry period" variable.

The significant amount of variability explained by the "concentration gradient" variable (Fig. 9) indicates that it may be the major source of variability observed in P removal by SP and possibly a significant factor for variability in P removal for stormwater BMPs overall. Residual analysis performed on the model indicated no obvious problems with regression assumptions.

\subsection{Spatial distribution of removal}

There was no apparent spatial gradient of adsorbed $\mathrm{P}$ in the direction of flow; however, a weak spatial gradient against the direction of flow was observed (Fig. 10A). When a linear regression model was applied to this gradient, the coefficient of determination was low $\left(R^{2}=0.30\right)$. Iron concentrations also exhibited a spatial gradient against the direction of flow, which could be due to slower settling velocities for finer particles while loading the substrate into standing water. The association of $P$ sorption with particle size is consistent with Zhu et al. (2003). Further regression analysis strongly indicated Fe concentration as significant for explaining variation in P concentration (Fig. $10 \mathrm{~B}, R^{2}=0.74$ ). Adding spatial position as a regressor provided no further explanation for $P$ concentration variability, lending support to the lack of a spatial gradient, and hence a state of thermodynamic quasi-equilibrium.

\section{Conclusions}

Results indicate that P removal by SP depends strongly on the relative equilibrium between solution $\mathrm{P}$ and adsorbed $\mathrm{P}$ in the substrate. Direct conclusions from this research include the following: (1) iron-oxide sand filtration is capable of removing DP; (2) filter "age" based on percent of theoretical sorption capacity is a poor predictor of the lifetime of $\mathrm{P}$ removal in the CW; (3) P removal may not occur even with theoretical sorption sites remaining as predicted by isotherm testing if no concentration gradient exists; (4) $\mathrm{P}$ removal is inversely correlated with $\mathrm{pH}$; and (5) $\mathrm{P}$ removal is dependent on and directly correlated to the concentration gradient present between solution and adsorbed $P$.

If an experimental run is considered analogous to a storm event, $P$ removal by SP during a given event is likely dependent on previous loadings to the BMP in terms of mass and concentration from past events. As a general trend, effluent concentrations will likely converge with influent concentrations over time, assuming that no additional concentration gradient is established. This convergence may help explain the "irreducible concentrations" seen in field studies of stormwater BMPs and may explain any variation in the level of this concentration between sites due to different loading histories. Estimates of future effluent concentrations or load reductions from SP should include information about both average and maximum influent concentrations, sorption capacity of the media, and the amount of $\mathrm{P}$ currently adsorbed. In addition, $\mathrm{pH}$ of the system and the timing of hydrologic loadings may provide additional value for estimation.

Potential design considerations from this model include the following: (1) for the same BMP design, less P removal by SP may occur for a lower influent concentration than for a higher influent concentration; (2) for the same influent, $P$ removal in a BMP with less available sorption sites (less total volume or less sorption site density) will likely decrease and/or become negligible more quickly; (3) if influent concentration decreases significantly from a sustained higher level, P removal by SP may become negligible or even reverse; (4) substrates will likely gain additional concentration gradient slowly as P diffusion into micropores occurs; (5) concentration gradient may also be driven by influent concentration increase, addition of more sorption sites, or by harvesting $\mathrm{P}$ from the substrate; and (6) spatial gradients of $P$ in substrate may be a better indicator of remaining sorption potential than isothermderived maximums.

\section{Future work}

The rejuvenation process described involves at least three areas of future research: (1) dissolution of adsorbed $P$ into solution by promoting microbial reduction of iron-oxides; (2) precipitation and harvest of phosphate solids from the CW; (3) and renewal of ironoxide coatings in the substrate for further adsorption. In addition, further research is needed to validate the relationship between existing spatial gradients of adsorbed $\mathrm{P}$ in substrates and remaining sorption potential and validate the physical-process model and associated conclusions with cells in field conditions.

\section{Acknowledgements}

The authors would like to thank the National Science Foundation for providing support for students who worked on the project as a part of the NSF Research Experiences for Undergraduates grant. In addition, the authors would like to acknowledge assistance from exceptional faculty (Dr. Tess Wynn and Dr. Daniel Gallagher), staff (Laura Teany and Julie Jordan), and students (Molly Julian, Gina Hayes, Yemi Ojumu, Cody Newbill, Sarah Brahman, Cherona Levy, and Steven Sell). Lastly, the authors would like to acknowledge the contributions of Ecosolutions, LLC in the development of the UWF concept.

\section{References}

Arai, Y., Sparks, D.L., 2007. Phosphate reaction dynamics in soils and soil components: a multiscale approach. Adv. Agron. 94, 136-179.

Arias, C.A., Brix, H., 2005. Phosphorus removal in constructed wetlands: can suitable alternative media be identified? Water Sci. Technol. 51, 267-273.

Arias, C.A., Bubba, M.d., Brix, H., 2001. Phosphorus removal by sands for use as media in subsurface flow constructed reed beds. Water Res. 35, 1159-1168.

Atasoy, M., Palmquist, R.B., Phaneuf, D.J., 2006. Estimating the effects of urban residential development on water quality using microdata. J. Environ. Manage. 79, 399-408.

Camargo, J.A., Alonso, A., 2006. Ecological and toxicological effects of inorganic nitrogen pollution in aquatic ecosystems: a global assessment. Environ. Int. 32, 831-849.

Carleton, J.N., Grizzard, T.J., Godrej, A.N., Post, H.E., Lampe, L., Kenel, P.P., 2000. Performance of a constructed wetlands in treating urban stormwater runoff. Water Environ. Res. 72, 295-304.

Comings, K.J., Booth, D.B., Horner, R.R., 2000. Storm water pollutant removal by two wet ponds in Bellevue, Washington. J. Environ. Eng. 126, 321-330.

Coveney, M.F., Stites, D.L., Lowe, E.F., Battoe, R.C., 2002. Nutrient removal from eutrophic lake water by wetland filtration. Ecol. Eng. 19, 141-159.

Darke, A.K., Walbridge, M.R., 2000. Al and Fe biogeochemistry in a floodplain forest: implications for P retention. Biogeochemistry 51, 1-32.

Drizo, A., Frost, C.A., Grace, J., Smith, K.A., 2000. Phosphate and ammonium distribution in a pilot-scale constructed wetland with horizontal subsurface flow using shale as a substrate. Water Res. 34, 2483-2490.

Evans, E.A., Rusch, K.A., 2007. Phosphorus treatment capability of the marshland upwelling system under low background salinity conditions. Ecol. Eng. 30, $250-263$.

Farahbakhshazad, N., Morrison, G.M., 2003. Phosphorus removal in a vertical upflow constructed wetland system. Water Sci. Technol. 48, 43-50.

Fisher, T.R., Peele, E.R., Ammerman, J.W., Harding, L.W., 1992. Nutrient limitation of phytoplankton in Chesapeake Bay. Mar. Ecol. Prog. Ser. 82, 51-63.

Hogan, D.M., Waldbridge, M.R., 2007. Best management practices for nutrient and sediment retention in urban stormwater runoff. J. Environ. Qual. 36, 386-395.

Hunt, W.F., Wossink, A., 2003. The Economics of Structural Stormwater BMPs in North Carolina. UNC-WRRI, Raleigh, NC. 
Kadlec, R.H., 2005. Phosphorus removal in emergent free surface wetlands. J. Environ. Sci. Health A: Environ. Sci. Eng. Toxic Hazard. Subst. Control. 40, 1293iron. S

Kadlec, R.H., Wallace, S.D., 2009. Treatment Wetlands. CRC Press, Boca Raton, FL

Lantzke, I.R., Mitchell, D.S., Heritage, A.D., Sharma, K.P., 1999. A model of factors controlling orthophosphate removal in planted vertical flow wetlands. Ecol. Eng. $12,93-105$.

Li, H., Davis, A.P., 2009. Water quality improvement through reduction of pollutant loads using bioretention. J. Environ. Eng. 135, 567-576.

Lovley, D.R., 1991. Dissimilatory Fe(III) and Mn(IV) reduction. Microbiol. Rev. 55 259-287.

Luederitz, V., Eckert, E., Lange-Weber, M., Lange, A., Gersberg, R.M., 2001. Nutrient removal efficiency and resource economics of vertical flow and horizontal flow constructed wetlands. Ecol. Eng. 18, 157-171.

McBride, M.B., 1994. Environmental Chemistry of Soils. Oxford University Press, New York.

Naylor, S., Brisson, J., Labelle, M.A., Drizo, A., Comeau, Y., 2003. Treatment of freshwater fish farm effluent using constructed wetlands: the role of plants and substrate. Water Sci. Technol. 48, 215-222.

Pant, H.K., Reddy, K.R., Lemon, E., 2001. Phosphorus retention capacity of root bed media of sub-surface flow constructed wetlands. Ecol. Eng. 17, 345355.

Parry, R., 1998. Agricultural phosphorous and water quality: a US environmental protection agency perspective. J. Environ. Qual. 27, 258-261.

Paul, M.J., Meyer, J.L., 2001. Streams in the urban landscape. Annu. Rev. Ecol. Syst. $32,333-365$

Prochaska, C.A., Zouboulis, A.I., 2006. Removal of phosphates by pilot vertical-flow constructed wetlands using a mixture of sand and dolomite as substrate. Ecol. Eng. 26, 293-303.
R Development Core Team, 2009. R: A Language and Environment for Statistical Computing. Vienna, Austria, http://www.R-project.org.

Redshaw, C.J., Mason, C.F., Hayes, C.R., Roberts, R.D., 1990. Factors influencing phosphate exchange across the sediment-water interface of eutrophic reservoirs. Hydrobiologia 192, 133-245.

Schueler, T.R., 1996. Irreducible pollutant concentrations discharged from urban BMPs. Watershed Protect. Tech. 2, 369-372.

Shilton, A., Pratt, S., Drizo, A., Mahmood, B., Banker, S., Billings, L., Glenny, S., Luo, D., 2005. 'Active' filters for upgrading phosphorus removal from pond systems. Water Sci. Technol. 51, 111-116.

Smith, S.V., Renwick, W.H., Bartley, J.D., Budemeier, R.W., 2002. Distribution and significance of small, artificial water bodies across the United States landscape. Sci. Total Environ. 299, 21-36.

Sonzogni, W.C., Chesters, G., Coote, D.R., Jeffs, D.N., Konrad, J.C., Ostry, R.C., Robinson, J.B., 1980. Pollution from land runoff. Environ. Sci. Technol. 14, 148-153.

Strecker, E.W., Quigley, M.M., Urbonas, B.R., Jones, J.J., 2001. Determining urban storm water BMP effectiveness. J. Water Resour. Plan. Manage. 127, 144-149.

USEPA, 1994. Determination of Metals and Trace Elements in Water and Wastes by Inductively Coupled Plasma-Atomic Emission Spectrometry. US Environmental Protection Agency, Office of Research and Development, Cincinnati, OH (EPA Method 200.7).

USEPA, 2002. Urban Stormwater BMP Performance Monitoring. US Environmental Protection Agency, Office of Water, Washington, DC (EPA 821-B-02-001).

VDCR, 1999. Virginia Stormwater Management Handbook. Department of Conservation and Recreation, Division of Soil and Water Conservation, Richmond, VA

Zeng, L., Li, X., Liu, J., 2004. Adsorptive removal of phosphate from aqueous solutions using iron-oxide tailings. Water Research (Oxford) 38, 1318-1326.

Zhu, T., Maehlum, T., Jenssen, P.D., Krogstad, T., 2003. Phosphorus sorption characteristics of a light-weight aggregate. Water Sci. Technol. 48, 93-100. 